\title{
Cianobactérias perifíticas em dois ambientes lênticos da planície de inundação do alto Rio Paraná, PR, Brasil
}

\author{
IRAÚZA A. FONSECA ${ }^{1}$ e LILIANA RODRIGUES ${ }^{1,2}$
}

(recebido: 26 de agosto de 2004; aceito: 1 de dezembro de 2005)

\begin{abstract}
Periphytic cyanobacteria in two lentic environments from the upper Paraná River floodplain). The Clara and Garças lagoons represent lentic environments from the floodplain in the upper Paraná River. Thirty six taxa were found, representing four orders (Chroococcales, Oscillatoriales, Nostocales and Stigonematales) and ten families (Synechococcaceae, Chroococcaceae, Merismopediaceae, Nostocaceae, Rivulariaceae, Borziaceae, Pseudanabaenaceae, Phormidiaceae, Oscillatoriaceae and Mastigocladaceae) of cyanobacteria. The most representative family was Pseudanabaenaceae, numbering seven taxa, followed by Oscillatoriaceae and Nostocaceae, both numbering six taxa. Among the 36 taxa, 22 were recorded for the first time in the floodplain of upper Paraná River.
\end{abstract}

Key words - cyanobacteria, floodplain, Paraná river, periphyton, taxonomy

RESUMO - (Cianobactérias perifíticas em dois ambientes lênticos da planície de inundação do alto Rio Paraná). As lagoas Clara e das Garças são ambientes lênticos inseridos na planície de inundação do alto Rio Paraná. Foram descritos 36 táxons distribuídos em quatro ordens (Chroococcales, Nostocales, Oscillatoriales e Stigonematales) e dez famílias (Synechococcaceae, Chroococcaceae, Merismopediaceae, Nostocaceae, Rivulariaceae, Borziaceae, Pseudanabaenaceae, Oscillatoriaceae, Phormidiaceae e Mastigocladaceae) de cianobactérias. A família de maior representatividade foi Pseudanabaenaceae, com sete táxons, seguida de Oscillatoriaceae e Nostocaceae, ambas com seis táxons. Dos 36 táxons, 22 são descritos pela primeira vez para a planície de inundação do alto Rio Paraná.

Palavras-chave - cianobactéria, perifíton, planície de inundação, Rio Paraná, taxonomia

\section{Introdução}

As mudanças entre os períodos de águas altas e baixas na planície alagável do alto Rio Paraná e a dinâmica criada pelo pulso de inundação diferenciam este ecossistema, propiciando-lhe uma elevada diversidade e produtividade (Agostinho \& Zalewiski 1996, Junk 1996). Os ambientes lênticos desta planície, por serem caracteristicamente rasos, sustentam grandes bancos de macrófitas aquáticas, que possibilitam um desenvolvimento abundante de algas perifíticas e metafíticas. Dentre estas algas destacam-se as cianobactérias, tanto por seus aspectos benéficos, quanto prejudiciais.

Segundo Chorus \& Bartram (1999), cianobactérias apresentam grande importância econômica. São importantes produtoras primárias e em geral têm alto valor nutritivo para organismos heterotróficos. Por outro lado, o seu crescimento abundante, principalmente em reservatórios de águas de abastecimento público, cria um sério transtorno.

1. Universidade Estadual de Maringá, Programa de Pós-graduação em Ecologia de Ambientes Aquáticos Continentais, PEA, Nupélia, Bloco G-90, Av. Colombo 5790, 87020-900 Maringá, PR, Brasil.

2. Autor para correspondência: 1rodrigues@nupelia.uem.br
A correta identificação das espécies é um dos mais sérios problemas enfrentado dentro deste grupo, onde somente em torno de $5 \%$ a $10 \%$ da diversidade de cianobactérias de biótopos extremos e tropicais é conhecida. Portanto, para trabalhos experimentais e ecológicos, o estudo taxonômico é uma tarefa indispensável, oferecendo uma boa avaliação da diversidade de cianobactérias (Komárek 2003). De acordo com Senna \& Magrin (1999), a taxonomia é a base de todo conhecimento científico e sem esta ferramenta não se faz ciência em qualquer momento do processo cognitivo.

A meta central desta pesquisa foi ampliar o conhecimento sobre a composição de cianobactérias, apresentando informações sobre distribuição geográfica e variabilidade populacional. O presente trabalho constitui-se em uma contribuição pioneira para o conhecimento taxonômico específico de cianobactérias em ambientes lênticos da planície alagável do alto Rio Paraná.

\section{Material e métodos}

Área de estudo - As lagoas Clara e das Garças estão localizadas na planície de inundação do alto Rio Paraná, nas proximidades do Município de Porto Rico (Estado do Paraná), 
divisa com o Estado do Mato Grosso do Sul. Esses dois ambientes situam-se entre as coordenadas $22^{\circ} 40^{\prime}-22^{\circ} 45^{\prime} \mathrm{S} \mathrm{e}$ $53^{\circ} 15^{\prime}-53^{\circ} 25^{\prime} \mathrm{W}$, respectivamente (figura 1 ).

A Lagoa Clara não apresenta comunicação com o canal principal do Rio Paraná. Está localizada na Ilha Porto Rico, possuindo profundidade média de $1,2 \mathrm{~m}$ e extensos bancos de macrófitas aquáticas em toda sua área (aproximadamente $0,91 \mathrm{ha})$

A Lagoa das Garças, situada na margem direita do Rio Paraná e com o qual se comunica permanentemente através de um estreito canal, possui aproximadamente $2 \mathrm{~km}$ de extensão e $150 \mathrm{~m}$ de largura. Apresenta a região litorânea com grande riqueza de macrófitas aquáticas, destacando-se Eichhornia azurea Kunth.

Métodos - Foram feitas coletas semestrais, no ano de 2001, sempre em réplicas, nos períodos de águas altas (fevereiro) e baixas (agosto), vinculadas ao programa "Pesquisas Ecológicas de Longa Duração - PELD sítio 6".

Para fins comparativos, padronizou-se o tipo de substrato, que consistiu de pecíolos de Eichhornia azurea Kunth no estádio adulto, por ser a macrófita aquática presente e bem representada nos dois ambientes. O material perifítico foi removido do substrato para frascos Wheaton $(150 \mathrm{~mL})$ com lâmina inoxidável e jatos d'água destilada, sendo fixado e preservado com lugol 5\%.

Para análise taxonômica foram preparadas 20 lâminas semipermanentes em média ou até não serem registradas novas ocorrências. Essa análise foi realizada em microscópio óptico, acoplado com ocular micrometrada, em objetiva de 100X. As ilustrações foram realizadas em microscópio binocular, acoplado com ocular micrometrada e câmara-clara da marca Nikon, em objetiva de 100X. Para a visualização da mucilagem foi utilizado corante do tipo nanquim.

As amostras estão depositadas no Herbário da Universidade Estadual de Maringá (HUM/UEM), em Maringá, sob as numerações:

BRASIL. ParanÁ: Porto Rico, planície de inundação do alto Rio Paraná, Lagoa Clara, 9-II-2001, I.A. Fonseca s.n., (HUM10485, HUM10486); 20-VIII-2001, I.A. Fonseca s.n., (HUM10487 e HUM10488); Lagoa das Garças, 9-II-2001, I.A. Fonseca s.n., (HUM11454, HUM11455); 20-VIII-2001, I.A. Fonseca s.n., (HUM11456 e HUM11457).

A identificação das cianobactérias foi fundamentada em obras clássicas (Geitler 1932, Desikachary 1959, Cocke 1967, Prescott 1982, Komárek \& Anagnostidis 1998, entre outras) e regionais (Campos \& Senna 1989, Senna 1992, 1994, 1996; Sant'Anna \& Azevedo 1995, Azevedo et al. 1996, entre outras).

Os táxons foram ordenados seguindo o enquadramento taxonômico proposto por Komárek \& Anagnostidis (1986, 1989, 1998), Anagnostidis \& Komárek (1988, 1990).

\section{Resultados e Discussão}

Foram registrados 29 táxons na Lagoa Clara e 16 na Lagoa das Garças, totalizando 36 táxons, distribuídos

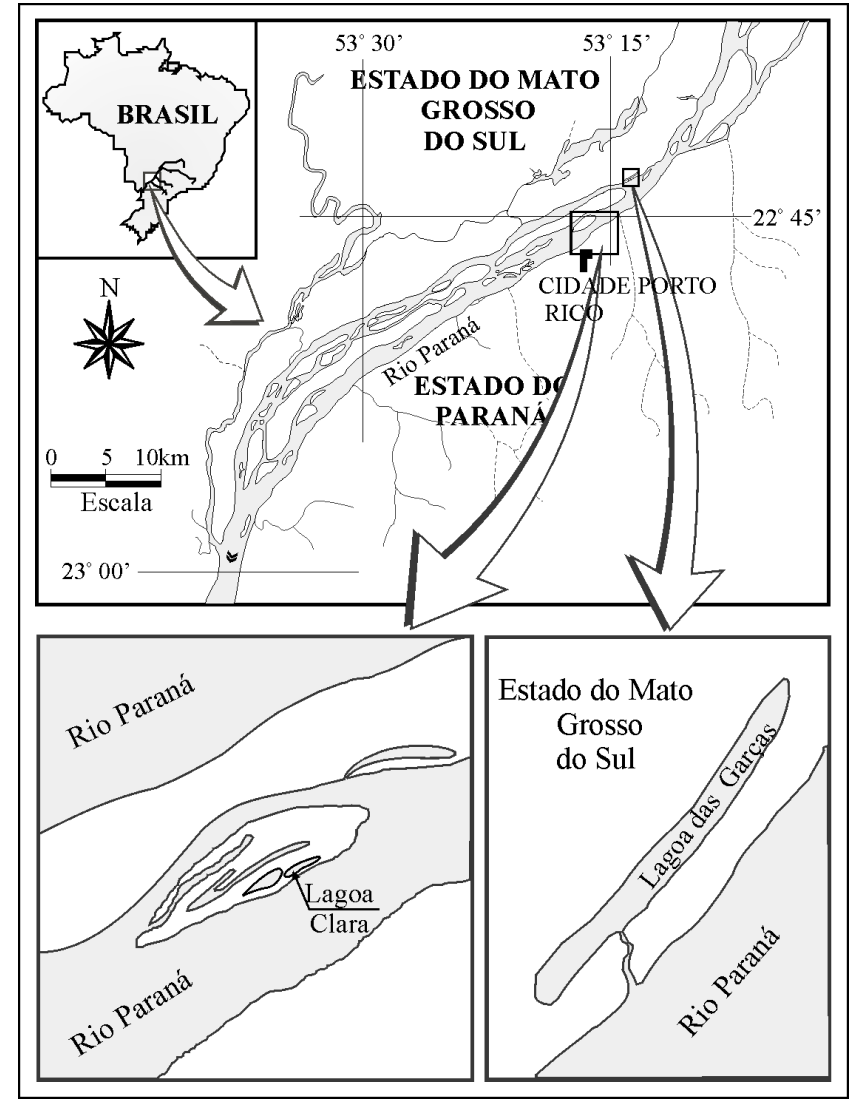

Figura 1. Localização dos dois ambientes amostrados na planície de inundação do alto Rio Paraná, Lagoa Clara e Lagoa das Garças.

Figure 1. Localization of the two environments sampling in the floodplain in upper Paraná River, Clara Lagoon and Garças Lagoon.

em quatro ordens e em dez famílias. Deste total, 22 táxons foram citados pela primeira vez para a planície de inundação do alto Rio Paraná.

\section{CHROOCOCCALES}

\section{Chroococcaceae}

\section{Chroococcus Nägeli}

Chroococcus minutus (Kützing) Nägeli, Gatt. Einz. Algen:46. 1849.

= Protococcus minutus Kützing, Phyc. Gener.:168. 1843.

Figura 3

Colônias com 2-4 células, células esféricas ou semiesféricas após a divisão, 5,3-5,9 $\mu \mathrm{m}$ diâm., verdeazuladas, inseridas em mucilagem, não lamelada, hialina; conteúdo celular homogêneo. 
Material examinado: HUM11454, HUM11455.

Registro da ocorrência na planície de inundação do alto Rio Paraná, em literatura: Lagoa das Garças e Ressaco do Pau Veio (Rodrigues \& Bicudo 2001:239).

Segundo Silva (1991), Chroococcus minutus (Kützing) Nägeli apresenta bainha lamelada, diâmetro celular sem bainha de 9,0-11,8 $\mu$ m e diâmetro celular com bainha de 10,6-15,0 $\mu$ m. Já Peres \& Senna (1998) e Senna (1992) registram C. minutus com características morfológicas e morfométricas $(4,8-5,3 \mu \mathrm{m}$ e 4,0-7,4 $\mu \mathrm{m}$, respectivamente) semelhantes aos espécimes constatados na planície alagável do alto Rio Paraná.

Merismopediaceae

Chave de identificação para os táxons identificados

1. Células solitárias ou aos pares Synechocystis aquatilis

1. Células formando colônias . (Merismopedia) 3

2. Colônias tabulares Merismapedia duplex

3. Espaço entre as células maior que duas vezes o diâmetro celular

3. Espaço entre as células menor que uma vez o diâmetro celular...

2. Colônias não tabulares Merismapedia tenuissima Aphanocapsa parasitica

\section{Aphanocapsa Nägeli}

Aphanocapsa parasitica (Kützing) Komárek \& Anagnostidis, Preslia, Praha 67:15. 1995.

Figura 4

Colônias arredondadas, microscópicas; colônias mais ou menos densa; mucilagem incolor; células esféricas, 1,5-2,1 $\mu \mathrm{m}$ diâm.

Material examinado: HUM10485, HUM10486.

Registro da ocorrência na planície de inundação do alto Rio Paraná, em literatura: primeira citação.

\section{Merismopedia Meyen}

Merismopedia duplex Playfair, Proceed. Lin. Soc. N. S. W. 42:633. 1918.

Figura 5

Colônias pequenas, com 8 células; espaço entre as células maior que duas vezes o diâmetro celular; mucilagem fina, difluente, hialina, células esféricas ou ovais, 2,8-5,1 $\mu$ m diâm.

Material examinado: HUM10485, HUM10486.

Registro da ocorrência na planície de inundação do alto Rio Paraná, em literatura: primeira citação.

$\mathrm{Na}$ população analisada, alguns espécimes apresentaram o diâmetro celular superior ao estabelecido em Komárek \& Anagnostidis (1998), que fazem referência a até $4,2 \mu \mathrm{m}$ de diâmetro. Entretanto, as demais características morfológicas estão condizentes com a circunscrição da espécie.
Merismopedia tenuissima Lemmermann, Bot. Zbl. 76:154. 1898.

Figura 6

Colônias tabulares, geralmente retangulares, com 16-32 células subesféricas ou esféricas, semi-esféricas após a divisão celular, imersas em bainha tênue e hialina; células 1,2-1,8 $\mu$ m diâm.; conteúdo celular homogêneo.

Material examinado: HUM10485, HUM10486, HUM11454, HUM11455.

Registro da ocorrência na planície de inundação do alto Rio Paraná, em literatura: Rio Paraná (Oliveira et al. 1994:162, fig. 16).

\section{Synechocystis Sauvageau}

Synechocystis aquatilis Sauvageau, Bull. Soc. Bot. Fr. 34:104. 1892.

Figura 2

Células globulares ou ovais, aos pares após a divisão celular, 4,2-6,1 $\mu \mathrm{m}$ diâm.

Material examinado: HUM10485, HUM10486.

Registro da ocorrência na planície de inundação do alto Rio Paraná, em literatura: primeira citação.

\section{SYNECHOCOCCACEAE}

Synechococcus Nägeli

Synechococcus mundulus Skuja, Nova Acta Reg. Soc. Sci. Upsal., Ser. 4, 18:1. 1964.

Figura 7 
Célula solitária, ou 2 após a divisão, alongadas com pólos arredondados, sem envelope mucilaginoso individual, 6,8-12,7 $\mu \mathrm{m}$ compr., 3,4-6,8 $\mu \mathrm{m}$ diâm.; conteúdo celular granuloso.

Material examinado: HUM10485, HUM10486.

Registro da ocorrência na planície de inundação do alto Rio Paraná, em literatura: primeira citação.

\section{NOSTOCALES}

\section{RIVULARIACEAE}

Chave de identificação para os táxons identificados

1. Tricomas curtos, constritos; não formando pêlo hialino . Calothrix brevissima

1. Tricomas longos, não constritos; formando pêlo hialino Calothrix fusca

Calothrix Agardh ex Bornet \& Flahault

Calothrix brevissima G.S. West, Journ. Linn. Soc. Bot. 38:180, tab. 10, fig. 8. 1907.

Figura 15

Filamentos em grupo, 7,5-8,0 $\mu \mathrm{m}$ diâm., bainha homogênea, hialina, fina. Tricomas curtos, cilíndricos, retos; células subquadráticas, 3,0-5,9 $\mu \mathrm{m}$ diâm., 4,2-5,9 $\mu \mathrm{m}$ compr.; conteúdo celular homogêneo; heterocito 6,8-8,9 $\mu$ m diâm.

Material examinado: HUM10485, HUM10486.

Registro da ocorrência na planície de inundação do alto Rio Paraná, em literatura: Lagoa das Garças (Rodrigues \& Bicudo 2001:239).

Calothrix fusca (Kützing) Bornet \& Flahault, Rév. I, p. 364.1886.

= Mastichothrix fusca Kützing, Phyc. germ. p.323. 1843.

Figura 14

Filamentos solitários ou em grupo, 11,0-12,0 $\mu \mathrm{m}$ diâm., bainha homogênea, incolor usualmente delgada; tricomas não constritos, curvos; células quadráticas, 6,1-8,0 $\mu \mathrm{m}$ diâm., 8,5-11,0 $\mu \mathrm{m}$ compr.; heterocito arredondado, subcônico, basal, único, 7,0-12,0 $\mu \mathrm{m}$ diâm.

Material examinado: HUM10485, HUM10486, HUM11454, HUM11455.

Registro da ocorrência na planície de inundação do alto Rio Paraná, em literatura: Lagoa das Garças (Rodrigues \& Bicudo 2001:239)

\section{Nostocaceae}

Chave de identificação para os táxons identificados

1. Heterocitos terminais 2

2. Acineto adjacente ao heterocito Cylindrospermum muscicola

2. Acineto não adjacente ao heterocito Cylindrospermopsis raciborskii

1. Heterocitos intercalares Nostoc cf. commune

3. Tricomas apoheterocíticos (Anabaena) 4

3. Tricomas paraheterocíticos Anabaena sphaerica

4. Tricomas sem envelope mucilaginoso

4. Tricomas com envelope mucilaginoso Anabaena affinis

5. Células esféricas, 5,5-6,0 $\mu \mathrm{m}$ diâm. Anabaena cylindrica

5. Células cilíndricas 3,5-3,8 $\mu \mathrm{m}$ diâm. 5

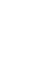


subesférico, 5,2-7,2 $\mu$ m diâm., 8,5-10,0 $\mu \mathrm{m}$ compr.; não foram observados acinetos.

Material examinado: HUM10485, HUM10486, HUM11454, HUM11455.

Registro da ocorrência na planície de inundação do alto Rio Paraná, em literatura: primeira citação.

Este táxon é facilmente distinguido dos demais táxons de Anabaena que possuem bainha mucilaginosa pela proporção comprimento/largura, que confere às células um aspecto cilíndrico alongado.

Anabaena sphaerica Bornet \& Flahault, Rév. Nost. Hét. p.228. 1888.

Figura 9

Tricomas solitários, retos, sem bainha mucilaginosa; células esféricas ou em forma de barril, 5,1-6,0 $\mu \mathrm{m}$ diâm., 3,4-4,2 $\mu$ m compr., sem aerótopos; célula apical arredondada; heterocitos 5,9 $\mu \mathrm{m}$ diâm., 6,1-7,6 $\mu \mathrm{m}$ compr.; acinetos não observados.

Material examinado: HUM11454, HUM11455.

Registro da ocorrência na planície de inundação do alto Rio Paraná, em literatura: primeira citação.

Cylindrospermum Kützing ex Bornet \& Flahault

Cylindrospermum muscicola Kützing, Phyc. germ. p.173. 1845.

Figura 12

Tricomas com células de 3,4-3,8 $\mu$ m diâm., 3,8-5,1 $\mu \mathrm{m}$ compr., levemente constrito na parede celular; células com um aerótopo; heterocito alongado, 5,7-6,5 $\mu \mathrm{m}$ diâm., 7,6-7,8 $\mu \mathrm{m}$ compr., acinetos elípticos, episporo liso, 6,0 $\mu \mathrm{m}$ diâm., 9,3 $\mu \mathrm{m}$ compr.

Material examinado: HUM10485, HUM10486.

Registro da ocorrência na planície de inundação do alto Rio Paraná, em literatura: Lagoa das Garças e Ressaco do Pau Véio (Rodrigues \& Bicudo 2001:239).

Cylindrospermopsis Seenayya \& Subba-Raju

Cylindrospermopsis raciborskii (Woloszynska) Seenayya \& Subba-Raju, Taxon. Biol. Blue-green Algae (Madras) p.52. 1972.

= Anabaena raciborskii Woloszynska, Bull. Int. Acad. Sci. Cracoviae Ser. B 6: 649. 1912.

Figura 11

Tricomas isolados, curvados ou retos; células de

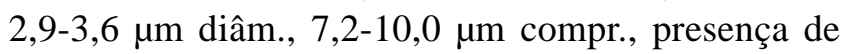
aerótopos; heterocito terminal, cônico, 3,4-4,2 $\mu \mathrm{m}$ diâm., 6,3-8,7 $\mu \mathrm{m}$ compr.; acinetos não observados.

Material examinado: HUM11454, HUM11455.
Registro da ocorrência na planície de inundação do alto Rio Paraná, em literatura: Rio Paraná e Canal Cortado (Oliveira et al. 1994:161, fig. 6).

Nostoc Vaucher

Nostoc cf. commune Vaucher ex Bornet \& Flahault, Hist. Conf. d'eau douce p.222. 1803.

Figura 13a-b

Colônias irregularmente globosas; tricomas curtos, curvos, densamente emaranhados; células em forma de barril, 3,0-4,0 $\mu \mathrm{m}$ diâm., 3,8-5,0 $\mu \mathrm{m}$ compr.; heterocitos terminais, oval, 4,9-5,1 $\mu \mathrm{m}$ diâm., 5,0-5,9 $\mu \mathrm{m}$ compr.; acinetos compridos, extremidades arredondadas, 4,1-4,2 $\mu$ m diâm., 5,9-6,5 $\mu \mathrm{m}$ compr.

Material examinado: HUM10485, HUM10486, HUM11456, HUM11457.

Registro da ocorrência na planície de inundação do alto Rio Paraná, em literatura: primeira citação.

Os espécimes encontrados nos dois ambientes lênticos analisados apresentaram medidas muito inferiores àquelas constatadas em Prescott (1982), ou seja, células com 4,0-6,0 $\mu \mathrm{m}$ diâm., 7,0 $\mu \mathrm{m}$ compr. e heterocitos com 7,0-8,4 $\mu \mathrm{m}$ diâm. Por esta razão preferiu-se registrar a ocorrência do táxon como Nostoc cf. commune Vaucher.

\section{OSCILLATORIALES}

BORZIACEAE

Chave de identificação para os táxons identificados

1. Células dolioliformes ............... Borzia trilocularis

1. Células moniliformes ...... Komvophoron schmidle

Borzia Cohn ex Gomont

Borzia trilocularis Cohn ex Gomont, Annls Sci. nat.: sér. 7, 16:198, pl. 6, fig. 5. 1982.

Figura 16

Tricomas solitários, curtos, constritos, 3-8 células; células, 5,4-6,9 $\mu$ m diâm., 2,8-4,2 $\mu$ m compr.; conteúdo celular homogêneo; parede celular não granulada, célula apical arredondada, sem espessamento.

Material examinado: HUM10485, HUM10486.

Registro da ocorrência na planície de inundação do alto Rio Paraná, em literatura: primeira citação.

Komvophoron Anagnostidis \& Komárek

Komvophoron schmidlei (Jaag) Anagnostidis \& Komárek, Algological Studies 50:373. 1988. 


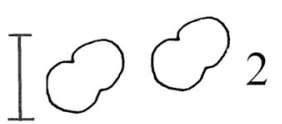

$$
1 \begin{array}{ll:l}
8 & 8 \\
8 & 8 & 5
\end{array}
$$

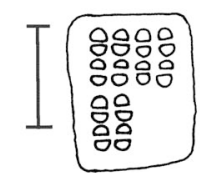

6

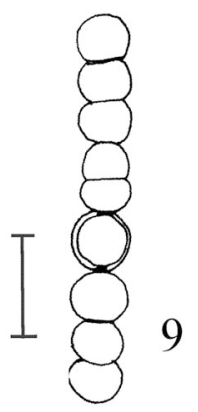

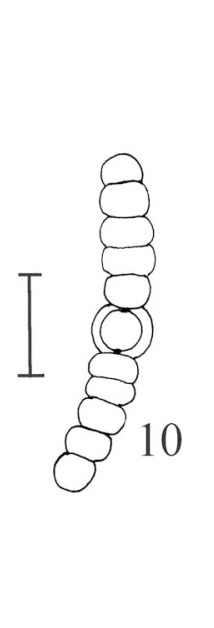
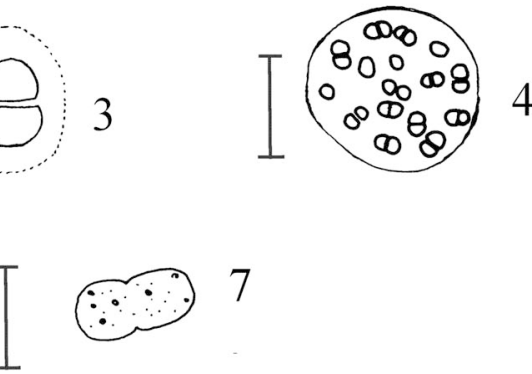
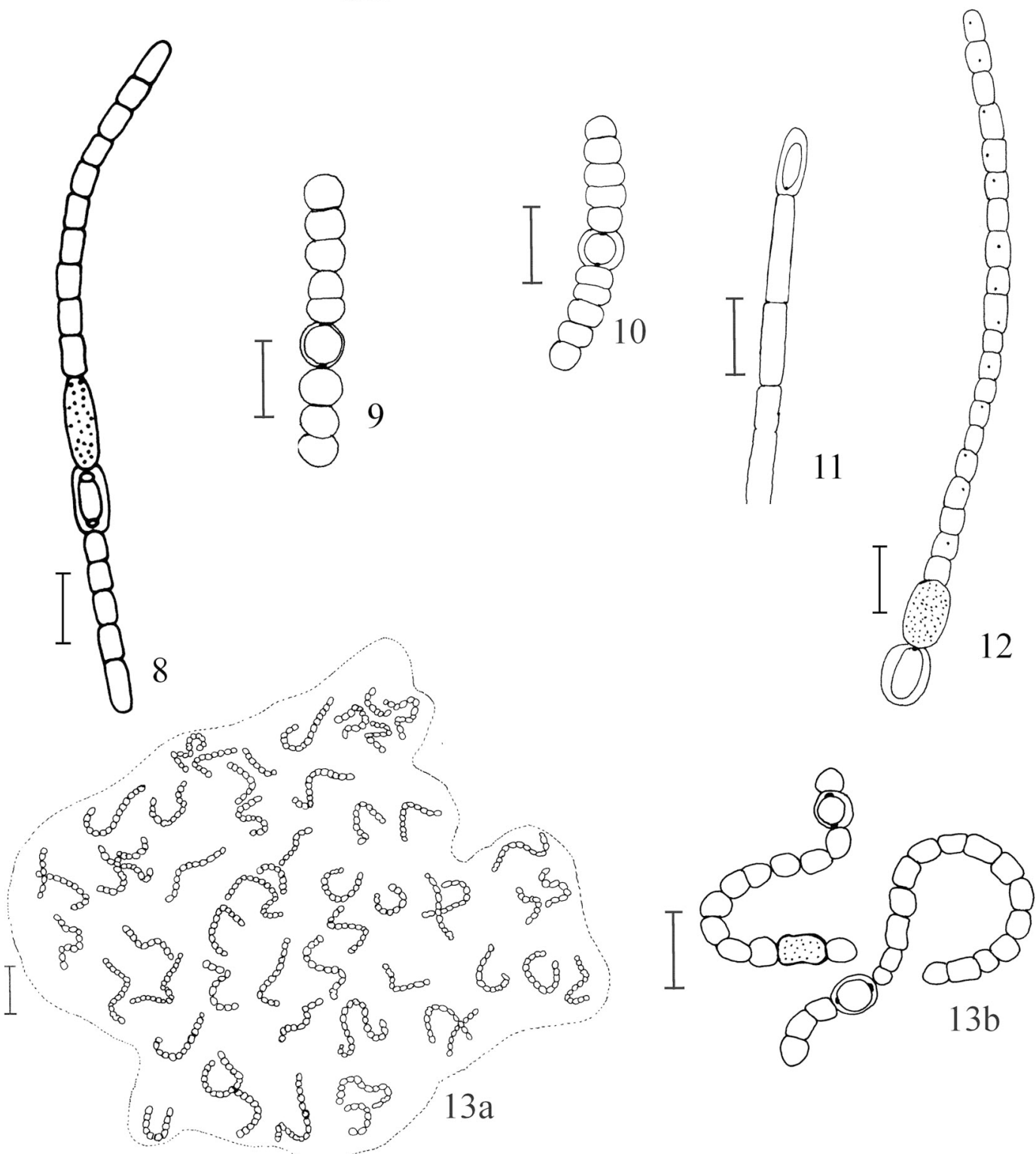

Figuras 2-13. Espécies de Cianobactérias. 2. Synechocystis aquatilis. 3. Chroococcus minutus. 4. Aphanocapsa parasitica. 5. Merismopedia duplex. 6. Merismopedia tenuissima. 7. Synechococcus mundulus. 8. Anabaena cylindrica. 9. Anabaena sphaerica. 10. Anabaena affinis. 11. Cylindrospermopsis raciborskii. 12. Cylindrospermum muscicola. 13. Nostoc cf. commune; a. colônia; b. tricomas. (Barras $=10 \mu \mathrm{m})$.

Figures 2-13. Species of Cyanobacterias. 2. Synechocystis aquatilis. 3. Chroococcus minutus. 4. Aphanocapsa parasitica. 5. Merismopedia duplex. 6. Merismopedia tenuissima. 7. Synechococcus mundulus. 8. Anabaena cylindrica. 9. Anabaena sphaerica. 10. Anabaena affinis. 11. Cylindrospermopsis raciborskii. 12. Cylindrospermum muscicola. 13. Nostoc cf. commune; a. colony; b. trichomes. $($ Bars $=10 \mu \mathrm{m})$. 
= Pseudanabaena schmidlei Jaag, Mitt. Naturf. Ges. Schaffhausen 14:117. 1938.

Figura 17

Tricomas solitários, curtos, simples, constritos, sem bainha mucilaginosa, células mais curtas do que longas. Células 4,0-4,25 $\mu$ m diâm., 2,9-3,8 $\mu$ m compr.

Material examinado: HUM10485, HUM10486.
Registro da ocorrência na planície de inundação do alto Rio Paraná, em literatura: primeira citação.

Conforme Anagnostidis \& Komárek (1988), o gênero Komvophoron difere do gênero Pseudanabaena por apresentar células em forma de barril. Também se diferencia do gênero Borzia por este último apresentar crescimento dos tricomas limitados.

\section{OsCillatoriaceAe}

\section{Chave de identificação para os táxons identificados}

1. Presença de bainha Lyngbya nigra

1. Ausência de bainha (Oscillatoria) 2

2. Tricomas constritos Oscillatoria annae

2. Tricomas não constritos Oscillatoria subbrevis

3. Tricomas menores que $14,0 \mu \mathrm{m}$ diâm 3

3. Tricomas maiores que $14,0 \mu \mathrm{m}$ diâm.

4. Parede celular granulada Oscillatoria limosa

4. Parede celular não granulada Oscillatoria princeps

\section{Lyngbya C. Agardh ex Gomont}

Lyngbya nigra Agardh ex Gomont, Syst. Alg. p. 312. 1824.

Figura 18

Filamentos flexuosos, 8,5-9,1 $\mu$ m diâm., bainha incolor, tricoma não constrito na parede celular; septo granulado; células retangulares, $1,8-2,2$ vezes mais longas do que largas, 7,6-8,0 $\mu \mathrm{m}$ diâm., 3,4-4,3 $\mu \mathrm{m}$ compr.; célula apical arredondada, com espessamento.

Material examinado: HUM10485, HUM10486.

Registro da ocorrência na planície de inundação do alto Rio Paraná, em literatura: primeira citação.

Oscillatoria Vaucher ex Gomont

Oscillatoria annae van Goor, Rec. Trav. Bot. Néerland. 15:289, pl. 2, fig. 1 a-c. 1918.

Figura 22

Tricoma geralmente reto, não atenuado, não capitado, constrito nos septos transversais, sem granulações no septo; célula apical hemisférica, células 2,8-3,2 vezes mais largas do que longas, 6,5-7,7 $\mu \mathrm{m}$ diâm., 2,0-2,7 $\mu \mathrm{m}$ compr.; conteúdo celular granulado.

Material examinado: HUM10485, HUM10486.

Registro da ocorrência na planície de inundação do alto Rio Paraná, em literatura: primeira citação.

Os espécimes encontrados por Senna (1996) no
Distrito Federal são mais largos do que os encontrados na planície de inundação do alto Rio Paraná, chegando a 9,7 $\mu$ m diâmetro. Entretanto, as demais características são condizentes com o material paranaense.

Oscillatoria limosa Agardh ex Gomont, Disp. Alg. Suec. p. 35. 1812.

Figura 20

Tricomas solitários, retos, não atenuados, não constritos; parede celular destituída de grânulos; célula apical arredondada, destituída de caliptra; células sempre mais largas do que longas, 15,0-16,1 $\mu \mathrm{m}$ diâm., 2,4-3,4 $\mu$ m compr.; conteúdo celular homogêneo.

Material examinado: HUM10485, HUM10486.

Registro da ocorrência na planície de inundação do alto Rio Paraná, em literatura: Ressaco do Pau Véio (Rodrigues \& Bicudo 2001:239)

Os espécimes paranaenses são diferentes dos descritos por Desikachary (1959), pois não apresentam membrana ligeiramente espessada na célula apical, mas se assemelham aos táxons encontrados por Sant'Anna \& Azevedo (1995). Desta forma, o espessamento da membrana apical parece não ser uma característica diagnóstica.

Oscillatoria princeps Vaucher ex Gomont, Ann. Sci. Nat., ser. 7, Bot. 16: 206, pl. 6, fig. 9. 1892.

Figura 21

Tricomas retos, pouco atenuados no ápice, não 


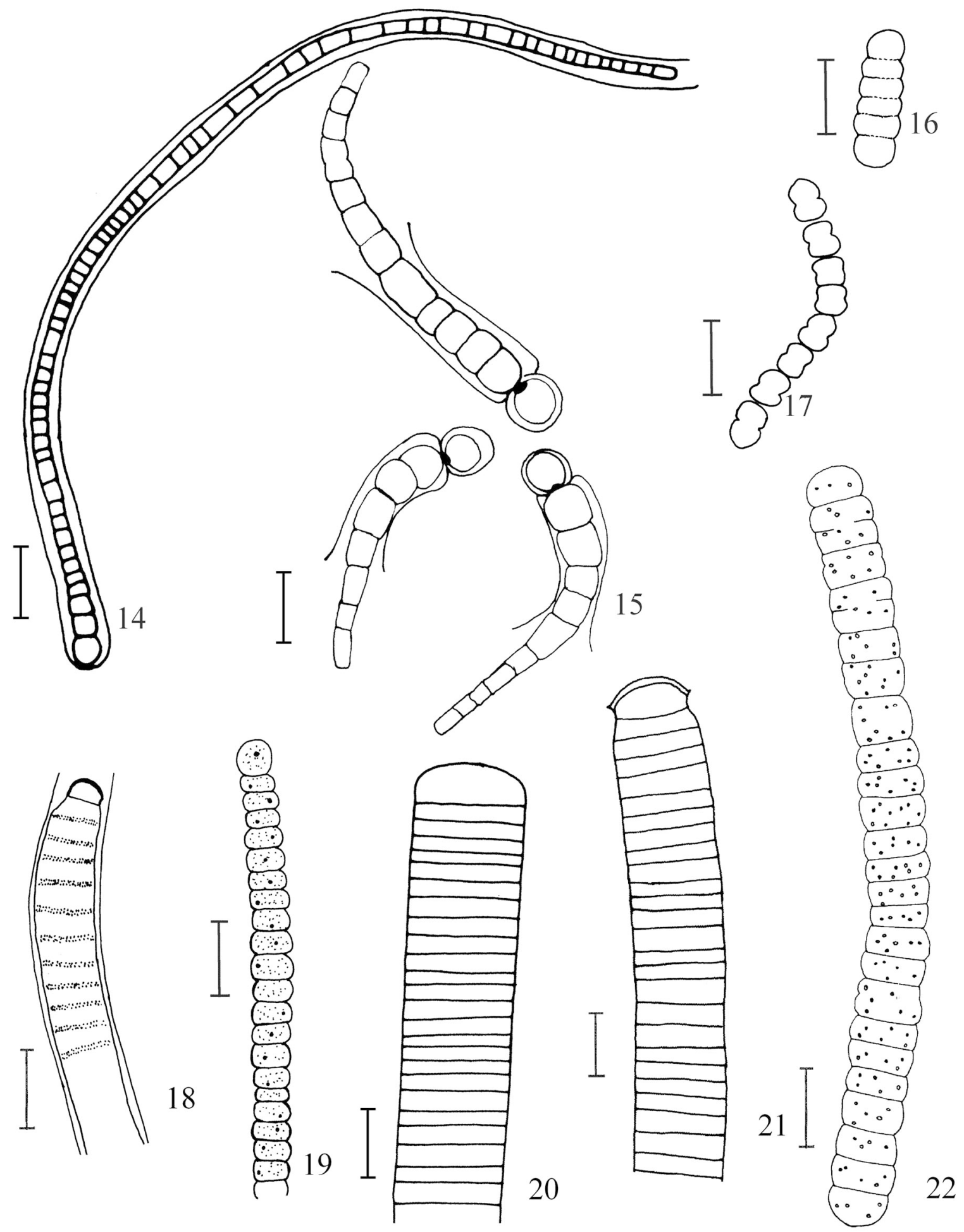

Figuras 14-22. Espécies de Cianobactérias. 14. Calothrix fusca. 15. Calothrix brevissima. 16. Borzia trilocularis. 17. Komvophoron schmidle. 18. Lyngbya nigra. 19. Trichodesmium lacustre. 20. Oscillatoria limosa. 21. Oscillatoria princeps. 22. Oscillatoria annae. $($ Barras $=10 \mu \mathrm{m})$.

Figures 14-22. Species of Cyanobacterias. 14. Calothrix fusca. 15. Calothrix brevissima. 16. Borzia trilocularis. 17. Komvophoron schmidle. 18. Lyngbya nigra. 19. Trichodesmium lacustre. 20. Oscillatoria limosa. 21. Oscillatoria princeps. 22. Oscillatoria annae. $($ Bars $=10 \mu \mathrm{m})$. 
capitado, sem constrição, sem granulações nos septos; células 5,5-5,7 vezes mais largas do que longas, conteúdo celular verde azulado, homogêneo, sem aerótopos; célula apical hemisférica, ausência de caliptra; tricomas 14,4-20,0 $\mu$ m diâm., 2,5-3,6 $\mu \mathrm{m}$ compr.

Material examinado: HUM10485, HUM10486, HUM11456, HUM11457.

Registro da ocorrência na planície de inundação do alto Rio Paraná, em literatura: primeira citação.

O diâmetro apresentou-se inferior ao encontrado por Sant'Anna \& Azevedo (1995) no Estado de São Paulo (19,0-45,0 um) e Azevedo et al. (1996), no Parque Estadual das Fontes do Ipiranga, SP
$(28,1-43,3 \mu \mathrm{m})$.

Oscillatoria subbrevis Schmidle, Bot. Jahrb. 30:243, pl. 4, fig. 7. 1901.

Figura 23

Tricomas retos, solitários, não atenuados, não constritos, parede celular não granulada, 6,4-6,9 $\mu \mathrm{m}$ diâm.; células retangulares, 2,0-3,8 vezes mais largas do que longas, 1,7-3,6 $\mu \mathrm{m}$ compr., conteúdo celular homogêneo, célula apical arredondada, sem caliptra.

Material examinado: HUM10485, HUM10486.

Registro da ocorrência na planície de inundação do alto Rio Paraná, em literatura: primeira citação.

\section{PHORMIDIACEAE}

Chave de identificação para os táxons identificados

1. Tricomas espiralados, unicelulares

Spirulina princeps

1. Tricomas geralmente retos, pluricelulares

2. Tricomas com bainha lamelada

2. Tricomas sem bainha lamelada Porphyrosiphon martensianus

3. Tricomas constritos 3

3. Tricomas não constritos Trichodesmium lacustre

4. Tricoma até $3 \mu \mathrm{m}$ diâm. Phormidium cf. willei

4. Tricoma com diâmetro maior do que $3 \mu \mathrm{m}$ Phormidium granulatum

\section{Phormidium Kützing ex Gomont}

Phormidium cf. willei (Gardner) Anagnostidis \& Komárek, Algological Studies 50:406. 1988.

Figura 30

Tricomas ligeiramente curvos, cilíndricos, não atenuados no ápice, não constritos; septos granulosos (2 grânulos em cada lado); células quadráticas ou mais longas do que largas, célula apicais arredondada; sem caliptra; 2,8-2,9 $\mu$ m diâm., 3,4-5,0 $\mu$ m compr.; conteúdo celular homogêneo.

Material examinado: HUM10485, HUM10486.

Registro da ocorrência na planície de inundação do alto Rio Paraná, em literatura: primeira citação.

Os exemplares do material paranaense diferiram dos identificados por Desikachary (1959), pois apresentaram grânulos nos septos transversais. Entretanto, foram enquadrados nesta espécie por seus demais caracteres morfométricos serem condizentes com a descrição daquele autor.

Phormidium granulatum (Gardner) Anagnostidis \& Komárek, Algological Studies 50:413. 1988.
= Oscillatoria granulata Gardner, Mem. N.Y. Bot. Gard. 7:37, pl. 8, fig. 71. 1927.

Figura 26

Tricomas retos, não atenuados, não capitados, não constritos; conteúdo celular homogêneo, com grânulos nos septos transversais; células 1,2 vezes mais largas do que longas, 4,2-4,7 $\mu \mathrm{m}$ diâm., 3,3-3,8 $\mu \mathrm{m}$ compr., célula apical ligeiramente curva, com bordas arredondadas, destituída de caliptra.

Material examinado: HUM10485, HUM10486.

Registro da ocorrência na planície de inundação do alto Rio Paraná, em literatura: primeira citação.

Os espécimes da planície de inundação do alto Rio Paraná diferiram daqueles descritos por Gardner (1927) por apresentarem grânulos finos e ausência de célula apical levemente espessada. Concorda-se com Peres \& Senna (1998) sobre a presença de granulações e ausência de espessamento da célula apical.

Porphyrosiphon Kützing ex Gomont

Porphyrosiphon martensianus (Meneghini ex 
Gomont) Anagnostidis \& Komárek, Algological Studies 50:409. 1988.

\section{Figura 24}

Filamentos solitários, longos, 8,7-16,0 $\mu \mathrm{m}$ diâm.; bainha lamelada, hialina, incolor; tricomas não capitados, não atenuados, não constritos, septos não granulados; conteúdo celular sem granulações; células 2,5-3,5 vezes mais largas do que longas, 7,0-8,5 $\mu \mathrm{m}$ diâm., 1,9-3,3 $\mu \mathrm{m}$ compr., célula apical arredondada, sem caliptra.

Material examinado: HUM10485, HUM10486.

Registro da ocorrência na planície de inundação do alto Rio Paraná, em literatura: Rio Paraná e Canal Cortado (Oliveira et al. 1994:161, fig. 7, como Lyngbya martensiana Meneghini), (Rodrigues \& Bicudo 2001:239, como Lyngbya martensiana Meneghini).

Spirulina Turpin ex Gomont

Spirulina princeps West \&. G.S. West, Trans. Linn. Soc., 2. Ser. Bot. 6:205. 1902.

Figura 25

Tricoma regularmente espiralado, 4,2-5,2 $\mu \mathrm{m}$ diâm., espirais 6,8-10,0 $\mu \mathrm{m}$ distância, 12,7-14,4 $\mu \mathrm{m}$ diâm.; conteúdo celular homogêneo.

Material examinado: HUM10485, HUM10486, HUM10487, HUM10488.
Registro da ocorrência na planície de inundação do alto Rio Paraná, em literatura: Lagoa das Garças (Rodrigues \& Bicudo 2001:239).

\section{Trichodesmium Ehrenberg ex Gomont}

Trichodesmium lacustre Klebahn, Forsch Ber. Biol. Stn Plön 3:13. 1895.

= Oscillatoria lacustris (Klebahn) Geitler, in Pascher, Süßwasserfl. 12: 362. 1925.

Figura 19

Tricomas formando feixes, retos, não atenuados, constritos, septos não granulosos; células $1,2-1,8$ vezes mais larga do que longa, 5,9-7,2 $\mu \mathrm{m}$ diâm., 3,0-4,0 $\mu \mathrm{m}$ compr., célula apical arredondada, desprovida de caliptra; conteúdo celular granulado, com aerótopos.

Material examinado: HUM10485, HUM10486, HUM11454, HUM11455.

Registro da ocorrência na planície de inundação do alto Rio Paraná, em literatura: primeira citação.

De acordo com Geitler (1932), os espécimes de O. lacustris (Klebahn) Geitler formam feixes, o que não foi observado no material proveniente dos dois ambientes lênticos da planície de inundação do alto Rio Paraná. A dimensão celular do material paranaense está de acordo com o descrito por Sant'Anna \& Azevedo (1995).

\section{Pseudanabaenaceae}

\section{Chave de identificação para os táxons identificados}

1. Tricomas constritos

2. Presença de grânulos Jaaginema geminatum

2. Ausência de grânulos .. 3

3. Presença de aerótopo subpolar

3. Presença de aerótopo central Pseudanabaena moniliformis

1. Tricomas não constritos Limnothrix sp.

4. Tricomas retos Leptolyngbya perelegans

4. Tricomas curvos Geitlerinema splendidum

5. Célula apical capitada 5

5. Célula apical não capitada 6

6. Presença de grânulos nos septos

6. Ausência de grânulos nos septos Jaaginema quadripunctulatum

7. Células até 2 vezes mais longas do que largas Leibleinia epiphytica

7. Células mais que 2 vezes mais longas do que largas Leptolyngbya thermalis 
Geitlerinema Anagnostidis

Geitlerinema splendidum (Greville ex Gomont) Anagnostidis, Plan. Syst. Evol. 164:43, fig. 2. 1989. Figura 28

Tricomas curvos, atenuados, não constritos, sem bainha, septos com 2-3 grânulos refringentes; células 1,3-3,0 vezes mais longas do que largas, 2,5-3,0 $\mu \mathrm{m}$ diâm., 4,2-9,2 $\mu$ m compr.; célula apical longo-cilíndica, capitada, mais longa que as outras, sem espessamento.

Material examinado: HUM10485, HUM10486.

Registro da ocorrência na planície de inundação do alto Rio Paraná, em literatura: Rio Paraná (Oliveira et al. 1994:161, fig. 9, como Oscillatoria splendida Greville), Lagoa das Garças (Rodrigues \& Bicudo 2001:239, como Oscillatoria splendida Greville).

Os táxons descritos por Sant'Anna \& Azevedo (1995), Peres \& Senna (1998) e Sant'Anna et al. (1983) apresentaram comprimento celular não ultrapassando 6,0 $\mu \mathrm{m}$. Entretanto, Campos \& Senna (1989) encontraram espécimes com comprimento celular de $(5,0) 6,0-9,0 \mu \mathrm{m}$, medidas semelhantes às registradas na planície alagável do alto Rio Paraná.

Jaaginema Anagnostidis \& Komárek

Jaaginema geminatum (Meneghini ex Gomont) Anagnostidis \& Komárek, Algological Studies 50: 395. 1988.

= Oscillatoria geminata Meneghini ex Gomont, Ann. Sci. nat., sér. 7, 16:2, pl. 7, fig. 6. 1882.

Figura 27

Tricomas solitários, retos, não atenuados, constritos; células retangulares, 1,4 a 2 vezes mais longas do que largas, 2,6-3,4 $\mu$ m diâm., 4,0-6,0 $\mu \mathrm{m}$ compr., célula apical retangular, com bordos arredondados, destituída de caliptra; citoplasma com grânulos grossos.

Material examinado: HUM10485, HUM10486.

Registro da ocorrência na planície de inundação do alto Rio Paraná, em literatura: Lagoa das Garças e Ressaco do Pau Véio (Rodrigues \& Bicudo 2001:239, como Oscillatoria geminata Meneghini ex Gomont).

A razão comprimento/largura é inferior a dos táxons descritos por Senna (1992), nas lagoas Joaquim Medeiros e dos Carás (2,0-4,6 vezes mais longas do que largas).

Jaaginema quadripunctulatum (Brühl \& Bisw) Anagnostidis \& Komárek, Algological Studies 50:396. 1988.

= Oscillatoria quadripunctulata Brühl \& Bisw, J. Dept. Sci. Calcutta Univ. 4:5, pl. 1, fig. 6. 1922.

Figura 31
Tricoma flexuoso, não atenuado, não capitado, sem constrição nos septos transversais, com granulação; citoplasma homogêneo, célula apical arredondada, destituída de caliptra, não espessada, células 2,8-3,0 vezes mais longas do que largas, 1,6-2,0 um diâm., 4,5-6,6 $\mu \mathrm{m}$ compr.

Material examinado: HUM11454, HUM11455.

Registro da ocorrência na planície de inundação do alto Rio Paraná, em literatura: primeira citação.

Leibleinia (Gomont) L. Hoffmann

Leibleinia epiphytica (Hieronymus) Anagnostidis \& Komárek, Algological Studies 50:394. 1988.

= Lyngbya epiphytica Hieronymus, in Kirchner in Engler \& Prantl, Nat. Pflanzenfam.1(1a): 67. 1900.

Figura 32

Filamentos solitários, curvos, 1,5-1,8 $\mu \mathrm{m}$ diâm.; bainha incolor, tricomas não atenuados, constritos, septos não granulosos; células 1,5-2,0 vezes mais longas do que largas, 1,0-1,2 $\mu \mathrm{m}$ diâm., 1,5-2,4 $\mu \mathrm{m}$ compr., célula apical arredondada.

Material examinado: HUM10487, HUM10488, HUM11454, HUM11455.

Registro da ocorrência na planície de inundação do alto Rio Paraná, em literatura: Lagoa das Garças (Rodrigues \& Bicudo 2001:239, como Lyngbya epiphytica Hieronymus).

Leptolyngbya Anagnostidis \& Komárek

Leptolyngbya perelegans (Lemmermann) Anagnostidis \& Komárek, Algological Studies 50:392. 1988.

= Lyngbya perelegans Lemmermann, Abh. Naturw. Ver. Bremen 16:355. 1899.

Figura 29

Filamentos solitários, retos, bainha estreita, incolor, homogênea; tricomas não atenuados, não constritos, septos com um grânulo em cada lado da parede celular; células 3,3-3,6 vezes mais longas do que largas, 1,4-1,8 $\mu \mathrm{m}$ diâm., 4,9-6,0 $\mu \mathrm{m}$ compr., célula apical cilíndrica, sem caliptra.

Material examinado: HUM11454, HUM11455.

Registro da ocorrência na planície de inundação do alto Rio Paraná, em literatura: primeira citação.

Leptolyngbya thermalis (Lemmermann) Anagnostidis \& Komárek, Algological Studies 50:393. 1988.

= Lyngbya limnetica Lemmermann, Bot. Zb. 76:154. 1898.

Figura 33 


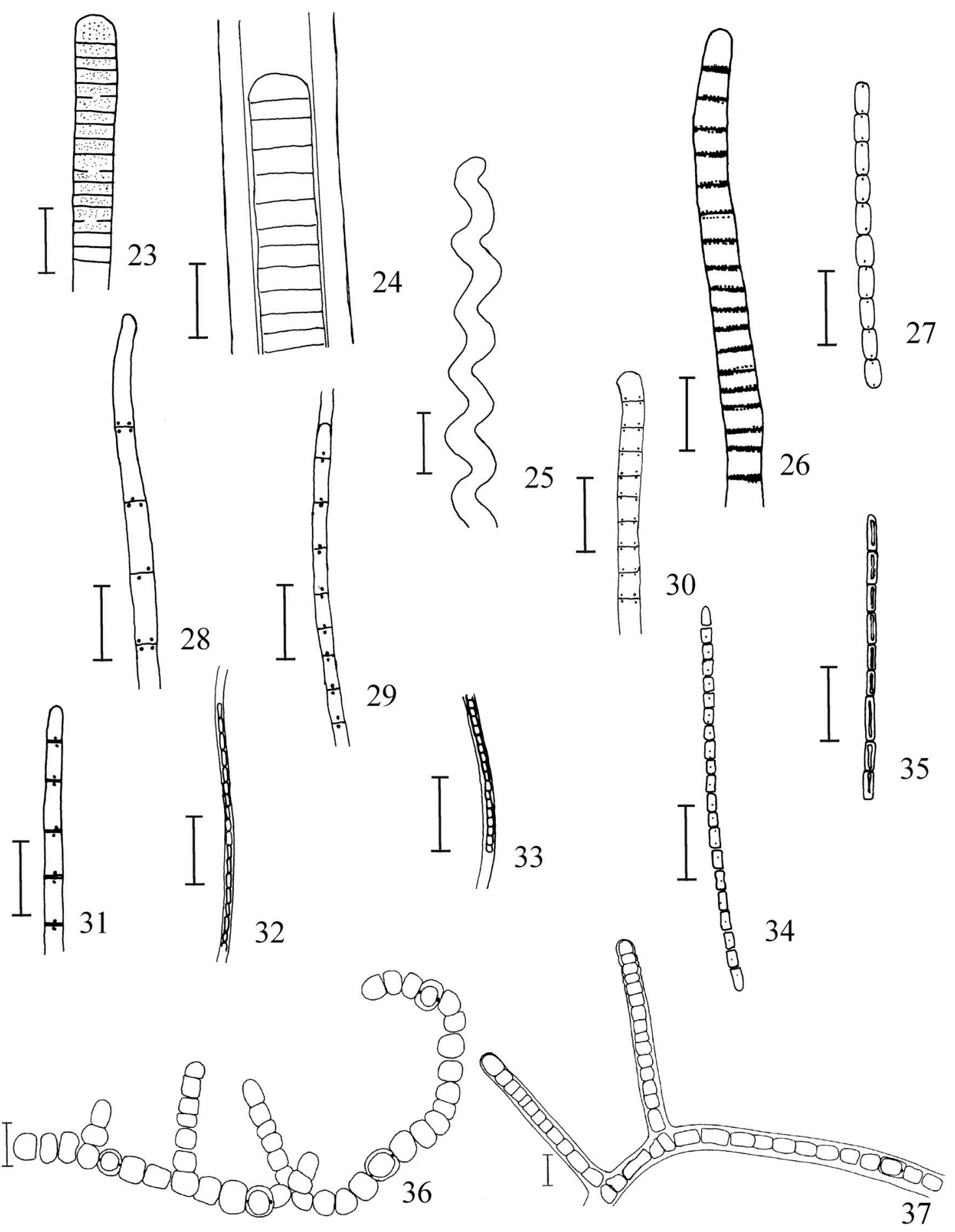

Figuras 23-37. Espécies de Cianobactérias. 23. Oscillatoria subbrevis. 24. Porphyrosiphon martensianus. 25. Spirulina princeps. 26. Phormidium granulatum. 27. Jaaginema geminatum. 28. Geitlerinema splendidum. 29. Leptolyngbya perelegans. 30. Phormidium cf. willei. 31. Jaaginema quadripunctulatum. 32. Leibleinia epiphytica. 33. Leptolyngbya thermalis. 34. Pseudanabaena moniliformes. 35. Limnothrix sp. 36. Hapalosiphon arboreus. 37. Hapalosiphon luteolus. $(\mathrm{Barras}=10 \mu \mathrm{m})$.

Figures 23-37. Species of Cyanobacterias. 23. Oscillatoria subbrevis. 24. Porphyrosiphon martensianus. 25. Spirulina princeps. 26. Phormidium granulatum. 27. Jaaginema geminatum. 28. Geitlerinema splendidum. 29. Leptolyngbya perelegans. 30. Phormidium cf. willei. 31. Jaaginema quadripunctulatum. 32. Leibleinia epiphytica. 33. Leptolyngbya thermalis. 34. Pseudanabaena moniliformes. 35. Limnothrix sp. 36. Hapalosiphon arboreus. 37. Hapalosiphon luteolus. $($ Bars $=10 \mu \mathrm{m})$. 
Filamentos solitários, flexuosos, 1,7 $\mu \mathrm{m}$ diâm.; bainha incolor, não lamelada; tricomas não atenuados, não constritos; septos não granulosos; células 2,2-2,5 vezes mais longas do que largas, 1,0-1,2 $\mu \mathrm{m}$ diâm., 2,5-2,7 $\mu \mathrm{m}$ compr., célula apical arredondada, destituída de caliptra; conteúdo celular homogêneo.

Material examinado: HUM11454, HUM11455.

Registro da ocorrência na planície de inundação do alto Rio Paraná, em literatura: primeira citação.

\section{Limnothrix Meffert}

Limnothrix sp.

Figura 35

Tricomas solitários, retos, sem bainha; células 3,7-5,2 vezes mais longas do que largas, levemente separadas, com 1,2-1,5 $\mu \mathrm{m}$ diâm., 4,5-7,8 $\mu$ m compr.; célula apical cilíndrico-arredondada, aerótopo no interior de cada célula.

Material examinado: HUM10485, HUM10486.

Este táxon assemelha-se morfologicamente a duas espécies do gênero Limnothrix, contudo os valores métricos encontrados em Geitler (1932) foram maiores. Em L. lauterbornii (Schmidle) Anagnostidis (Oscillatoria lauterbornii Schmidle), o diâmetro celular foi de 2,0-2,5 $\mu \mathrm{m}$, enquanto que em $L$. rosea (Utermöhl) Meffert (Oscillatoria rosea Utermöhl) o diâmetro celular foi de $3 \mu \mathrm{m}$, apresentando as demais características diagnósticas semelhantes.

Pseudanabaena Lauterbon

Pseudanabaena moniliformis Komárek \& Kling, Algological Studies 61:21. 1991.

Figura 34

Tricomas solitários, retos, curtos, constritos; células cilíndricas, 1,5-2,0 vezes mais longas do que

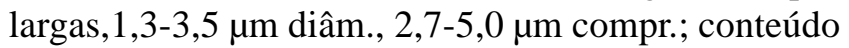
celular homogêneo; presença de aerótopos subpolar; ausência de grânulos na parede celular, célula apical arredondada, sem espessamento.

Material examinado: HUM10485, HUM10486, HUM11454, HUM11455.

Registro da ocorrência na planície de inundação do alto Rio Paraná, em literatura: primeira citação.

Os espécimes constatados por Azevedo et al. (1996), no Parque Estadual das Fontes do Ipiranga, diferem dos encontrados na planície alagável do alto Rio Paraná, pois no material paulista o comprimento celular foi maior. Porém, a razão largura/comprimento foi a mesma.

\section{STIGONEMATALES}

Mastigocladaceae

Chave de identificação para os táxons identificados

1. Filamentos até $8,0 \mu \mathrm{m}$ diâm.

Hapalosiphon arboreus

1. Filamentos maiores que $8,5 \mu \mathrm{m}$

diâm. Hapalosiphon luteolus

\section{Hapalosiphon Nägeli}

Hapalosiphon arboreus W. West \& G. S. West, Journ. Linn. Soc. Bot. 30:272. 1895.

Figura 36

Filamentos principais solitários, reto ou curvo, 5,8-8,0 $\mu \mathrm{m}$ diâm., bainha não evidente, incolor, não lamelada; tricomas unisseriados; células quadráticas a subesféricas, 5,1-6,5 $\mu \mathrm{m}$ compr., 5,8-7,1 $\mu \mathrm{m}$ diâm.; conteúdo homogêneo; ramos simples, perpendiculares ao filamento principal; heterocitos intercalares, subcilíndricos, 6,3-8,0 $\mu$ m diâm., 5,9 $\mu \mathrm{m}$ compr.

Material examinado: HUM11454, HUM11455.

Registro da ocorrência na planície de inundação do alto Rio Paraná, em literatura: primeira citação.

Hapalosiphon luteolus West \& G.S. West, Journ. Bot. 35:241. 1897.

Figura 37

Filamentos principais solitários, curvos, 8,5-10,0 $\mu \mathrm{m}$ diâm., bainha pouco lamelada; tricomas unisseriados; células subesféricas, 7,2-8,5 $\mu \mathrm{m}$ compr., 6,0-6,4 $\mu \mathrm{m}$ larg., heterocitos intercalares, subcilíndricos, 7,0-9,0 $\mu \mathrm{m}$ diâm., 5,0-7,0 $\mu \mathrm{m}$ compr.; ramos secundários com aproximadamente 15 células.

Material examinado: HUM10485, HUM10486, HUM11454, HUM11455.

Registro da ocorrência na planície de inundação do alto Rio Paraná, em literatura: primeira citação.

Agradecimentos - As autoras agradecem especialmente à Dra. Célia L. Sant'Anna pela colaboração na identificação dos táxons registrados; ao Nupélia (Núcleo de Pesquisas em Limnologia, Ictiologia e Aqüicultura); ao PEA (Programa de Pós-Graduação em Ecologia de Ambientes Aquáticos Continentais) da Universidade Estadual de Maringá, pelo apoio logístico; à Capes, pela concessão da bolsa de mestrado à primeira autora. Esta pesquisa fez parte do projeto PELD (Projeto Ecológico de Longa Duração) - sítio 6. 


\section{Referências bibliográficas}

AGOSTINHO, A.A. \& ZALEWISKI, M. 1996. A planície alagável do alto Rio Paraná: Importância e preservação. Editora da Universidade Estadual de Maringá, Maringá.

ANAGNOSTIDIS, K. \& KOMÁREK, J. 1988. Modern approach to the classification system of Cyanophytes, 3: Oscillatoriales. Algological Studies 80:327-472.

ANAGNOSTIDIS, K. \& KOMÁREK, J. 1990. Modern approach to the classification system of Cyanophytes, 5: Stigonematales. Algological Studies 59:1-73.

AZEVEDO, M.T.P., NOGUEIRA, N.M.C. \& SANT'ANNA, C.L. 1996. Criptógamos do Parque das Fontes do Ipiranga, São Paulo, SP. Algas, 8: Cyanophyceae. Hoehnea 23:1-38.

CAMPOS, I.F.P. \& SENNA, P.A.C. 1989. Nostocophyceae (Cyanophyceae) da Lagoa Bonita, Distrito Federal, Brasil. II. Revista Brasileira de Biologia 49:83-95.

CHORUS, I. \& BARTRAM, J. 1999. Toxic Cyanobacteria in Water: a guide to their public health consequences, monitoring and management. E \& FN SPON, Londres.

COCKE, E.C. 1967. The myxophyceae of North Carolina. Edwards Brothers, Michigan.

DESIKACHARY, T.V. 1959. Cyanophyta. Indian Council of Agricultural Research, New Delhi.

GARDNER, N.L. 1927. New Myxophyceae from Porto Rico. Memoirs of the New York Botanical Garden 7:1-144.

GEITLER, L. 1932. Cyanophyceae. In Dr. L. RABENHORST'S Kryptogamenflora von Deutschlands, Österreichs und der Schweiz (R. Kolkwitz, ed.). Akademische, Verlagsgesellschft, Leipzig.

JUNK, W.J. 1996. Ecology of floodplain: a challenge for tropical limnology. In Perspectives in Tropical Limnology (F. Schiemer \& K.T. Boland, eds.). Academic Publishing, Amsterdam, p. 255-265.

KOMÁREK, J. 2003. Planktic oscillatorialean cyanoprokariotes (short review according to combined phenotype and molecular aspects). Hydrobiologia 502:367-382.

KOMÁREK, J. \& ANAGNOSTIDIS, K. 1986. Modern approach to the classification system of Cyanophytes, 2: Chroococcales. Algological Studies 43:157-226.

KOMÁREK, J. \& ANAGNOSTIDIS, K. 1989. Modern approach to the classification system of Cyanophytes, 4: Nostocales. Algological Studies 82:247-345.
KOMÁREK， J. \& ANAGNOSTIDIS, K. 1998. Cyanoprokaryota: Chroococcales. In Sübwasserflora von Mitteleuropa (H. Ettl, G. Gärtner, H. Heynig \& D. Mollenhauer, eds.). G. Fischer, Stuttgart, p.1-546.

OLIVEIRA, M.D., TRAIN, S. \& RODRIGUES, L.C. 1994. Levantamento preliminar do fitoplâncton de rede (exceto Zygnemaphyceae) do rio Paraná, no município de Porto Rico, Paraná, Brasil. Revista Unimar 16:155-174.

PERES, A.C. \& SENNA, P.A.C. 1998. Cyanophyceae da Lagoa do Diogo, Planície de Inundação do Rio Mogi-Guaçu, Estação Ecológica do Jataí, Estado de São Paulo, Brasil. Hoehnea 25:195-214.

PRESCOTT, G.W. 1982. Algae of the Western great lakes area. Otto Koeltz Science Publishers, Koenigstein.

RODRIGUES, L. \& BICUDO, D.C. 2001. Similarity among periphyton algal communities in a lentic-lotic gradient of the upper Paraná river floodplain, Brazil. Revista Brasileira de Botânica 24:235-248.

SANT'ANNA, C.L., BICUDO, R.M.T. \& PEREIRA, H.A.S.L. 1983. Nostocophyceae (Cyanophyceae) do Parque Estadual da Ilha do Cardoso, Estado de São Paulo, Brasil. Rickia 10:1-27.

SANT'ANNA, C.L. \& AZEVEDO, M.T.P. 1995. Oscillatoriaceae (Cyanophyceae) from São Paulo State, Brazil. Nova Hedwigia 60:19-58.

SENNA, P.A.C. 1992. Estudo das Nostocophyceae (Cyanophyceae) do Distrito Federal, 2: Lagoas Joaquim Medeiros e dos Carás. Revista Brasileira Biologia 52:461-479.

SENNA, P.A.C. 1994. Cyanophyceae de la Région Est du District Fédéral, Brésil, 1. Bulletin du Jardin Botanique National du Belgique 63:81-100.

SENNA, P.A.C. 1996. Cyanophyceae from the Eastern Region of Distrito Federal, Brazil, 2. Bulletin du Jardin Botanique National du Belgique 65:73-102.

SENNA, P.A.C. \& MAGRIN, A.G.E. 1999. A importância da "boa" identificação dos organismos fitoplanctônicos para os estudos ecológicos. In Perspectivas da limnologia no Brasil. (M.L.M. Pompêo, ed.). Gráfica e Editora União, São Luís, p.131-146.

SILVA, S.M.F. 1991. Flora de cianobactérias marinhas bentônicas da Ilha da Inhaca, litoral sul de Moçambique. Hoehnea. 18:1-4. 